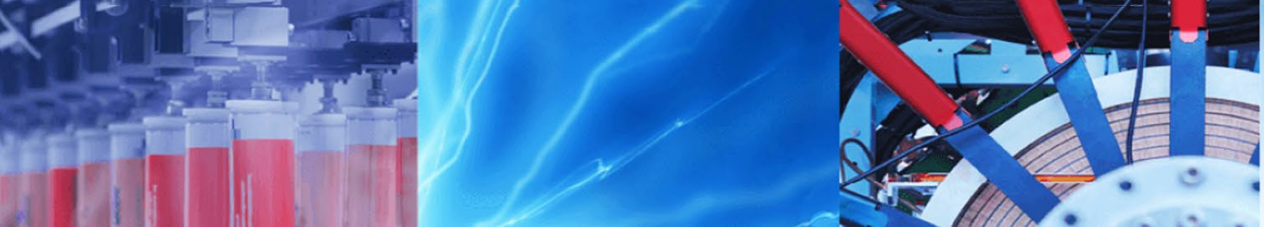

Research Article

\title{
Physicochemical properties of ambient pressure dried surface modified silica aerogels: effect of $\mathrm{pH}$ variation
}

\author{
Mangesh V. Khedkar ${ }^{1} \cdot$ Swapnil A. Jadhav ${ }^{1}$ - Sandeep B. Somvanshi ${ }^{1} \cdot$ Prashant B. Kharat $^{1} \cdot$ K. M. Jadhav ${ }^{1}$
}

Received: 30 January 2020 / Accepted: 10 March 2020 / Published online: 18 March 2020

(c) Springer Nature Switzerland AG 2020

\begin{abstract}
This work demonstrates the synthesis of hydrophobic silica aerogels from silicic acid with $\mathrm{pH}$ variations by using a costeffective and safe ambient pressure drying process. The work aims to evaluate the effect of $\mathrm{pH}$ variation on physicochemical properties of silica aerogels by standard techniques. In the present investigation, we have selected hexane as the solvent and trimethylchlorosilane/hexane was used to perform the surface modification of wet gel in order to elude the contraction and disintegration of gel association subsequent to a drying process. The effect $\mathrm{pH}$ on gelation in the form hydrolysis and condensation as well as on amorphous structure, physical properties such as density, thermal stability, surface area, pore-volume, pore radius, optical transmittance were investigated. FTIR spectroscopy was used to confirm the silylation (surface modification) of the prepared silica aerogel samples. Water contact angles were measured to verify the hydrphobic behaviour of all the samples. Among the prepared $\mathrm{pH}$ varied samples, the sample having $\mathrm{pH} \sim 5$ shows better results such as high optical transmittance, thermal stability, hydrophobicity and high surface area.
\end{abstract}

Keywords Silica aerogels $\cdot \mathrm{pH}$ variation $\cdot$ Surface modification $\cdot$ Hydrophobicity $\cdot$ XRD $\cdot$ TG-DTA

\section{Introduction}

The special class of materials having the air as main constituent (up to $98 \%$ ) and solid material as a minimal constituent (up to $2 \%$ ) are generally referred to as the 'Aerogels' [1]. The term aerogels became earmarked for the porous gels obtained by eliminating solvent from highly distended gels without or minimal collapsing of the gel network. Nowadays aerogels are emerging as an entirely new class of solid-state materials with open cell, large surface area $\left(\sim 1000 \mathrm{~m}^{2} / \mathrm{g}\right)$, low density $(\sim 0.03 \mathrm{~g} /$ $\mathrm{cm}^{3}$ ) low thermal conductivity $(0.02 \mathrm{~W} / \mathrm{m}-\mathrm{K})$ and highly porous structure ( 96\%) [2]. Typically, the structures of aerogels are built-up by particles with the greater part of the nanoscale pores which form an inorganic framework. As a consequence of these exceptional nanoscale structures, ultra-low-density with high porosity materials demonstrate many attention-grabbing and unusual properties $[3,4]$. Hence these remarkable properties of silica aerogel have many more applications such as optical, catalytic, super thermal insulator, insulated flask, and refrigerators, Cerenkov radiation detectors [5-7].

In the conventional approach, the aerogel preparation was carried out via a supercritical drying process [8]. In extremely critical drying procedures, elevated temperature and pressure with supercritical fluids are being used to remove a liquid component of a gel which is very risky and often hazardous as well as expensive also [9]. In the view of commercialization of aerogel products drying with siloxanes at high temperature and pressure with highly igneous solvent evacuation which is very risky [10]. In the synthesis of aerogel, the most enviable step is to abolish the extremely critical drying procedure. Therefore, interests upsurge in aerogel research to fabricate the samples

K. M. Jadhav, drjadhavkm@gmail.com | 'Department of Physics, Dr. Babasaheb Ambedkar Marathwada University, Aurangabad, Maharashtra 431004, India. 
of silica aerogels at a normal room temperature in ambient conditions which is an alternative preparation route [11]. In recent times, the production of silica aerogels via these safe techniques using low-cost precursors such as sodium silicate solution has been identified as a feasible approach.

For the preparation of high-quality nanostructured materials, the sol-gel technique is a simple and reliable process. The viewpoint of silica aerogels applications, to control their porous structures is very essential. The advantage of the sol to gel formation technique is better to control over size and microstructure [12, 13]. Using this approach, the properties and structures of silica aerogels can be tailored to specific applications by optimizing sol-gel processing parameters [14]. Although the preparation methods, precursor, solvents, silylating agent and different physicochemical parameters of silica aerogels are widely investigated, the reports on the effect of $\mathrm{pH}$ on the various physicochemical parameters of silica aerogels are rare.

Usually, in the preparation of silica aerogel, the condensation and the hydrolysis procedures are promoted by acids and bases [15]. This affects the microstructure of the gel and ultimately the gelation time and macroscopic properties due to aggregations of nonporous primary particles. The synthesis conditions also affect the aggregations influencing the particle size, pore formation, and chain branching. As a result, the macroscopic properties like pore size, porosity, bulk density, and surface area can be changed [16]. Very few research reports are available in the literature about the effect of $\mathrm{pH}$ on the physicochemical parameters of silica aerogel. Brinker et al. [17] were studied the impact of $\mathrm{pH}$ on the gel formation. Pope and AS Dorchehet al. [15] concluded from their report that $\mathrm{pH}$ not only affects the control of hydrolysis procedure and gelation but also the physicochemical parameters. Sarawade et al. [18] reported the influence of $\mathrm{pH}$ parameters on gelation. Katalin Sinko [19] investigated the impact of $\mathrm{pH}$ parameters on the properties of aerogels in a brief way. He reported that by varying the synthesis conditions and parameters structure of the porous materials can be tailored. Twej et al. [20] studied the correlation of $\mathrm{pH}$ with optical, morphological behaviour of aerogel samples. They reported that the $\mathrm{pH}$ variation can be used to control the optical parameters of silica aerogels. Thus, herein we investigated the physical and chemical parameters of aerogel samples with varied $\mathrm{pH}$ prepared at the ambient conditions. One of the reactions and processing parameters in the sol-gel synthesis is the $\mathrm{pH}$ which affects the physical parameters like porosity, density, strength, transparency, etc. in addition the chemical structure of the resulting gel [21].

To the date for the utilization in Cerenkov radiation detector silica aerogels are the lightest solid material available in the world with the sufficiently highest optical transparency $(\sim 90 \%)$ low refractive index $(\sim 1.01)$. Although in this case, the market is very limited, and it is requisite to demonstrate the aerogels with the lowest possible refractive index [22]. Thus, it can be observed through the literature that, the optical parameters of silica aerogels are not studied. In this report, we have prepared surface-modified silica aerogel by using trimethylchlorosilane under the safe, un-hazardous and less-expensive ambient pressure drying method and sodium silicate as a precursor to augment the reproducible nature of silica aerogels production. We intended on the single synthesis parameter that is the $\mathrm{pH}$ value of silicic acids prepared from sodium silicate solution passing through Amberlite ion exchange resin. However, in the literature, a shortage of studies covering the influence of $\mathrm{pH}$ on the physicochemical parameters was observed. In the current case, we made a sincere attempt to report a detailed description covering the influence of $\mathrm{pH}$ on the different physicochemical parameters of the silica aerogel samples prepared at ambient atmosphere.

\section{Experimental procedure}

Systematic preparation of hydrophobic silica aerogel was carried out at a different values of $\mathrm{pH}$ using the cost-effective and safest ambient condition process. To synthesize silica aerogels by sol-gel process, least expensive and non-toxic sodium silicate solution (M.W. $122.06 \mathrm{~g} / \mathrm{mol}$, specific gravity $1.43, \mathrm{pH} \sim 13$ ) was used as a silica precursor to obtain hydrogels. In the first step, sodium silicate solution was diluted $\left(\mathrm{Na}_{2} \mathrm{SiO}_{3}: \mathrm{H}_{2} \mathrm{O}\right.$ ratio kept as $\left.1: 6\right)$ to get specific gravity of 1.05 . Secondly, $\mathrm{Na}_{2} \mathrm{SiO}_{3}$ solution was passed through Amberlite (IR-120H) ion exchange resin (purchased from SDFCL) to eliminate the barrier of $\mathrm{Na}^{+}$ and to obtian the silicic acid ( $\mathrm{pH} \sim 2$ to 3 ). Then, $\mathrm{NH}_{4} \mathrm{OH}$ $\left(\mathrm{NH}_{3}\right.$ (M.W.17.03) diluted in distilled water) of $1 \mathrm{~N}$ as a base catalyst was added to silicic acid for the adjustment of $\mathrm{pH}$ values. Sample coded as A, B, C, D was prepared with different $\mathrm{pH}$ values viz. 4, 5, 6, 7 respectively, and it was observed that the formation of the hydrogel of different $\mathrm{pH}$ took the time gap. To strengthen the silica network, the obtained hydrogel was kept in a hot water bath for $3 \mathrm{~h}$ aging process at $50^{\circ} \mathrm{C}$. The aged hydrogel was exchanged with $30 \mathrm{ml}$ methanol $\left(\mathrm{CH}_{3} \mathrm{OH}, \mathrm{M} . W .32 .04 \mathrm{~g} / \mathrm{mol}\right)$ to replace the water molecules presented in pores of gel. The same process was repeated for two times in $24 \mathrm{~h}$ at $50^{\circ} \mathrm{C}$. In the next step, the methanol in the gel was exchanged with $30 \mathrm{ml}$ Hexane $\left(\mathrm{C}_{6} \mathrm{H}_{14}, \mathrm{M} . W .86 .18 \mathrm{~g} / \mathrm{mol}\right)$ for $24 \mathrm{~h}$ at $50^{\circ} \mathrm{C}$. After the pore fluid decanted from hexane, the surface of the prepared samples was modified by Trimethylchlorosilane (TMCS $/ \mathrm{C}_{3} \mathrm{H}_{9} \mathrm{SiCl}, \mathrm{M} . W .108 .64 \mathrm{~g} / \mathrm{mol}$, purity $98 \%$ ) and 
hexane mixture (TMCS to hexane ratio was kept 1:1) at $50^{\circ} \mathrm{C}$ in $24 \mathrm{~h}$. After modification of wet gel, it was kept for drying process under ambient pressure at $50^{\circ} \mathrm{C}$ and $150^{\circ} \mathrm{C}$ for $1.25 \mathrm{~h}$ and $2.25 \mathrm{~h}$ respectively. The flowchart for the preparation of silica aerogel is displayed in Fig. 1.

The density $(\rho)$ of the obtained aerogel samples was evaluated by the mass $(\mathrm{M})$ to volume $(\mathrm{V})$ ratio $(\rho=\mathrm{M} / \mathrm{V})$ where mass was determined by the microbalance and volume by filling samples in a column of known volume. The TG-DTA technique was used to estimate the thermal behaviour of prepared samples in terms of retention of hydrophobicity. For this purpose, the heating rate was kept as $10^{\circ} \mathrm{C}$ per minute in the nitrogen atmosphere from $25^{\circ} \mathrm{C}$ (room temperature) to $1000^{\circ} \mathrm{C}$. Fourier Transform Infrared (FT-IR, Bruker Germany, Vertex 70 model) spectra were recorded to affirm the chemical changes in the range of $500-4000 \mathrm{~cm}^{-1}$ which gave the evidence about the numerous chemicals bonding such as $\mathrm{Si}-\mathrm{O}-\mathrm{Si}$ network, $-\mathrm{OH}, \mathrm{Si}-\mathrm{OH}, \mathrm{C}-\mathrm{H}-\mathrm{CH}_{3}$, and $\mathrm{Si}-\mathrm{C}$ [23]. High-Resolution Field-Emission Scanning Electron Microscopy technique (Model: FEl Quanta 200F) with EDS was used to analyze the microstructure and elemental mapping respectively of aerogel samples [24]. UV-Vis spectrophotometer (Avaspec-ULSi2048L, with a resolution of $0.05 \mathrm{~nm}$ ) was used to carry out optical transparency of prepared samples over the range $250-700 \mathrm{~nm}$ to construct transmittances curves [25]. The nitrogen sorption isotherms recorded using Brunauer-Emmet-Teller (BET, Quantachrome Instruments v5.2) were used to determine the specific surface area, pore volume and pore radius. Before BET measurement the samples were degassed at $200^{\circ} \mathrm{C}$ to remove the moisture and other unwanted content. The distribution of pore size is estimated by the BJH method. The contact angle measurements were carried out with the help of indegeneous contact angle meter consisting CCD camera controlled with computer.

\section{Results and discussion}

The silica aerogels can be produced via sol-gel technique, this process includes multiple steps like hydrolysis and condensation, gelation, surface modification, and drying, etc. Sol to gel transition mainly involves in the preparation of hydrogels [18]. In this transition the sols become very much viscous even if the beaker is tilted ceases to move, this transition is referred to as gelation. During the final stage of sol aging linear structures are formed, that transforms into the nano-globules, gelation period and the mass per volume mainly depend on the $\mathrm{pH}$ of the reaction. The condensation polymerization indicates that an ionic mechanism involves an aqueous solution while formations of silica gel. The structural configuration of the evolving gel network and final polymer are the main steps defined by the hydrolysis and condensation. The $\mathrm{pH}$ can be effectively influenced by the relative rate condensation and hydrolysis process which can be significantly affected by the final structures of the prepared sample. The impact

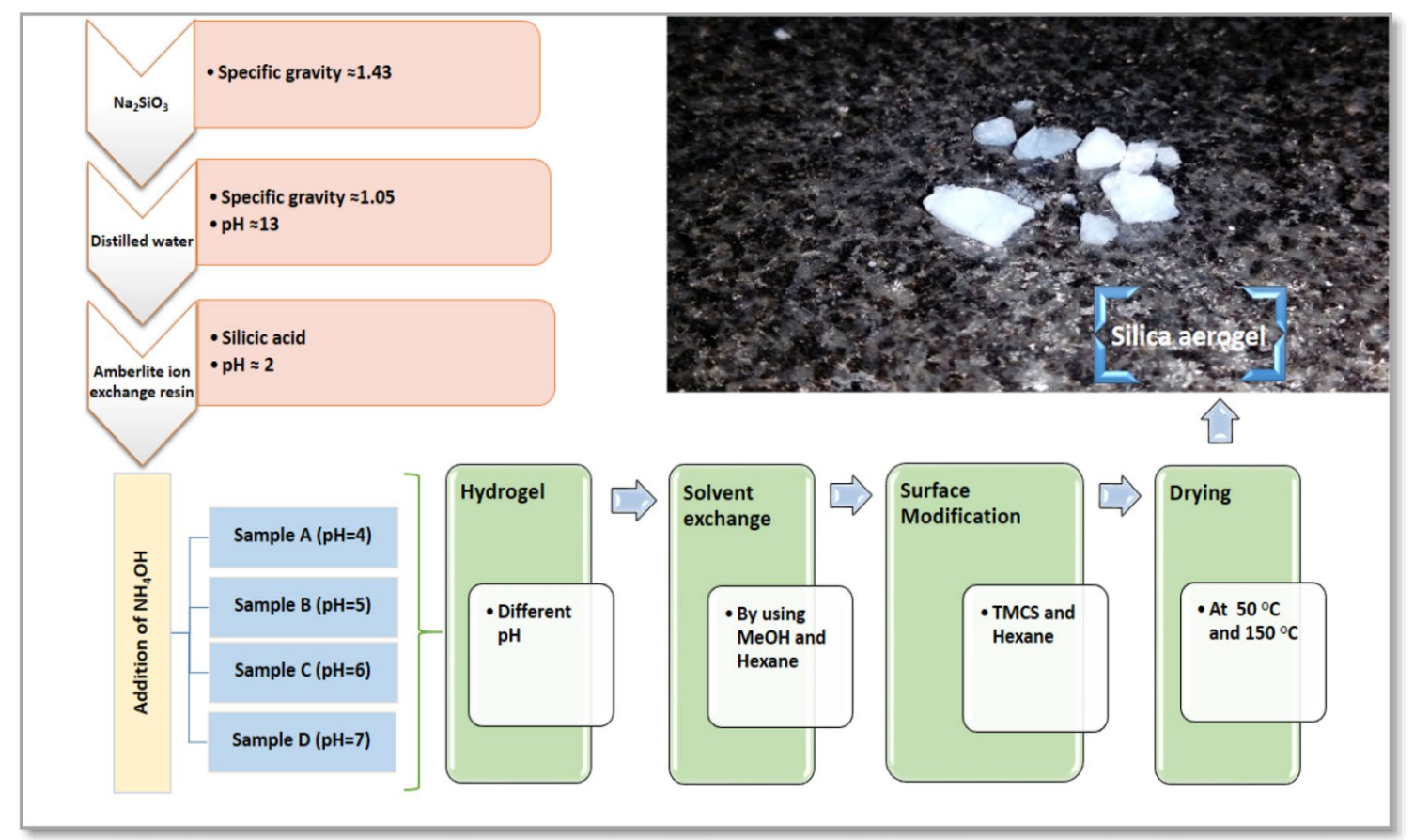

Fig. 1 Flowchart for the preparation of silica aerogel 
of the $\mathrm{pH}$ values on the gelation period has appeared in Fig. 2. At the $\mathrm{pH}$ values corresponding to 7 , the reaction rate for hydrolysis is very low and for the lowest reaction rate of condensation was at $\mathrm{pH}=5$. As the $\mathrm{pH}$ of the silica sol increased from 5 to 7 the time of gelation increases. As $\mathrm{pH}$ is less than or equal to 5 means under acid-catalyzed conditions are in the favor of hydrolysis reactions that limit condensation reactions $[18,20]$. Because of this clustering of silica agglomerate at the quicker time comparatively which helps to form a porous silica network of threedimensional in a very short time. At a low $\mathrm{pH}$ range of silica sol, particles of the silica have very few ionic charges. Because of the rate condensation or diffusion rates, aggregation may be restricted. At acidic conditions $(\mathrm{pH} 4-5)$ the tempo of the hydrolysis process lowers and condensation rate increases which in the favor of growing in siloxane

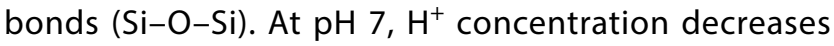
hence hydrolysis rate is low as well as sols of silica are having -ve charge and thus, they resist mutually because of this fact, the time required to form the gel at this range increases. At $\mathrm{pH}$ range around 5 gelation time is very less because silica monomers are transformed into particles, at the same time which aggregates into gel network [19].

The density of prepared silica aerogels samples varied systematically. Under the basic conditions, silica gels obtain a more branched network and under the acidic conditions, it's a more chain-like network. At pH 7 (neutral condition) condensation process dominates the hydrolysis process. At neutral $\mathrm{pH}$ value, the molecule of precursors agglomerated to lesser or more or denser particles [26, 27]. An increase in density with preparation $\mathrm{pH}$ is a good agreement with surface area as well as FE-SEM is clearly shown aggregation $\mathrm{pH}$ at the natural condition.

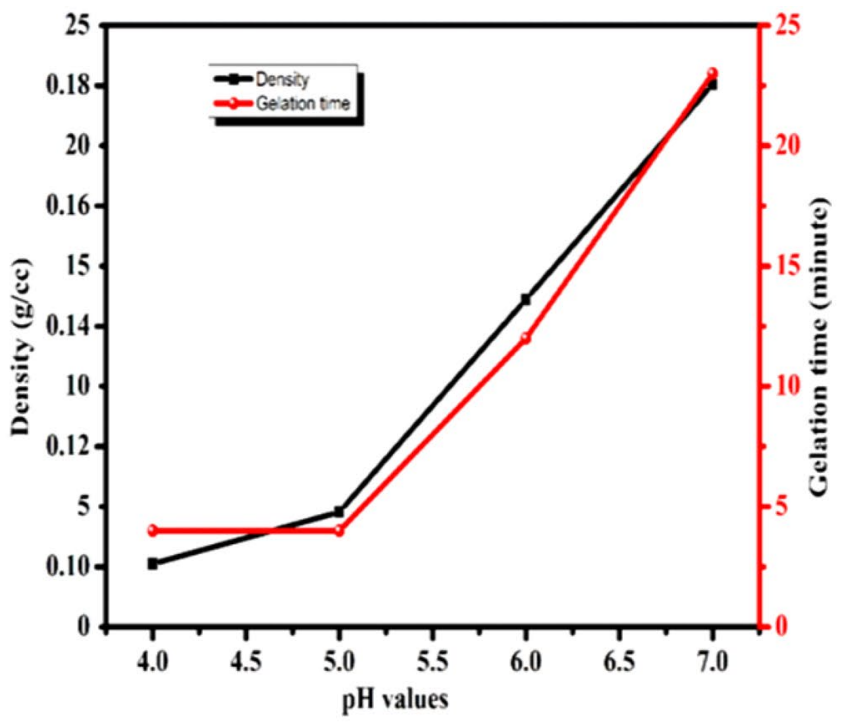

Generally, silica aerogels are hydrophilic in nature with the humid surroundings it structure get destroyed to avoid this problem in the present work we modified the surface of prepared samples by employing TMCS. Thus, the silica aerogel samples become hydrophobic in nature with surface modification. In the surface modification process $-\mathrm{CH}_{3}$ groups are attached to the gel surface $[28,29]$. To understand the thermal stability of the prepared aerogels sample at different $\mathrm{pH}$ values was examined using TGA-DTA as shown in Fig. 3. Exothermic peaks observed at $521{ }^{\circ} \mathrm{C}, 522{ }^{\circ} \mathrm{C}, 536^{\circ} \mathrm{C}$ and $512{ }^{\circ} \mathrm{C}$ associated with the oxidation of methylsilyl group with $\mathrm{pH}$ value 4, 5,6 and 7 respectively. Beyond these temperatures there is significant weight loss because of the decomposition of modified methylsilyl groups on the silica network were observed. It indicates that the hydrophobic stability of the prepared sample could be maintained up to $521^{\circ} \mathrm{C}, 522^{\circ} \mathrm{C}$, $536^{\circ} \mathrm{C}$ and $512{ }^{\circ} \mathrm{C}$ with pH value $4,5,6$ and 7 respectively.

Fourier transform infrared spectra (FT-IR) of the prepared samples has been confirmed the extent of surface modification (silylation) in silica aerogels with trimethylchlorosilane as a silylating agent as shown in Fig. 4. The broad absorption peak $\sim 1065 \mathrm{~cm}^{-1}$ in the FT-IR spectra corresponds to the $\mathrm{Si}-\mathrm{O}-\mathrm{Si}$ bonding (silica network) which helps to confirm the three-dimensional linking of $\mathrm{Si}-\mathrm{O}-\mathrm{Si}$ in the aerogels [30]. FT-IR spectra disclose that the strength of $\mathrm{Si}-\mathrm{O}-\mathrm{Si}$ peaks increases with increasing $\mathrm{pH}$ value. From the figure, it indicates that the absorption close to $1250 \mathrm{~cm}^{-1}$ corresponds to the deformation and stretching modes of $\mathrm{Si}-\mathrm{C}$ bond. The peak near to $840 \mathrm{~cm}^{-1}$ is linked with the $\mathrm{Si}-\mathrm{CH}_{3}$ bending. The attachment of $-\mathrm{CH}_{3}$ groups to the gel surface confirms the hydrophobic nature of the prepared silica aerogels [31]. FT-IR spectra revealed that

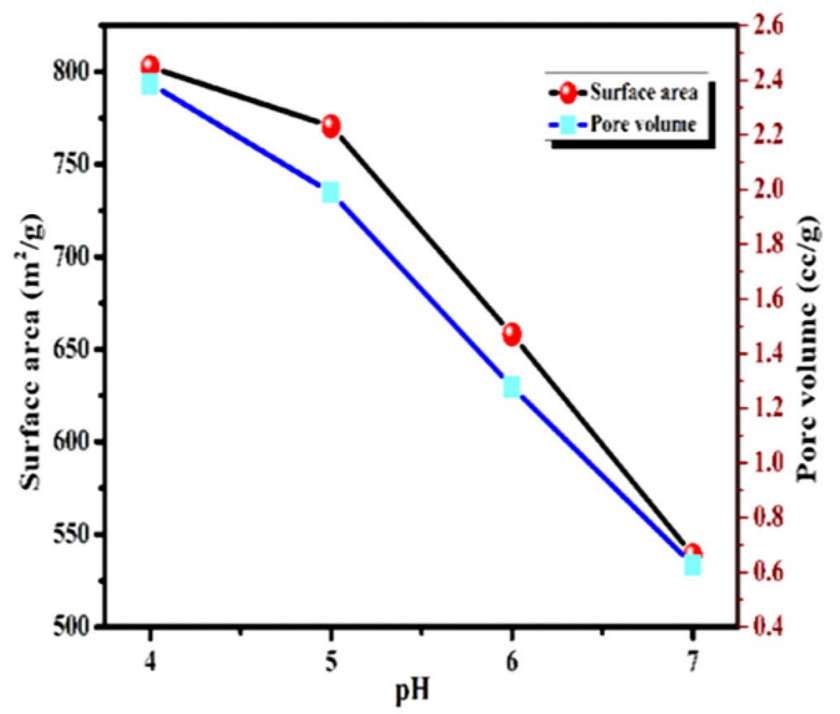

Fig. 2 Effect of pH on gelation time, density, surface area and pore volume of silica aerogels 

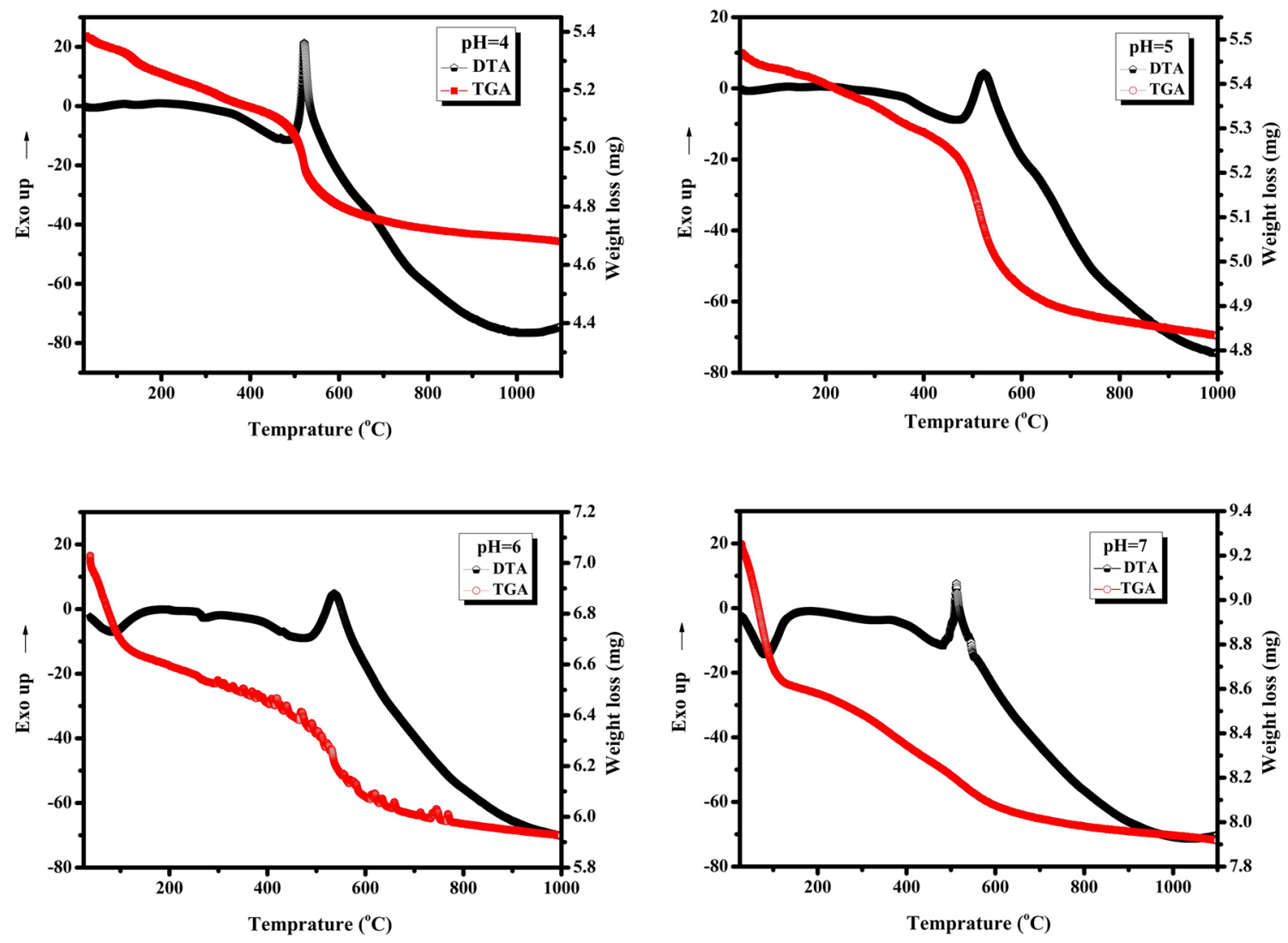

Fig. 3 TGA-DTA curves of silica aerogel sample at different $\mathrm{pH}$ value

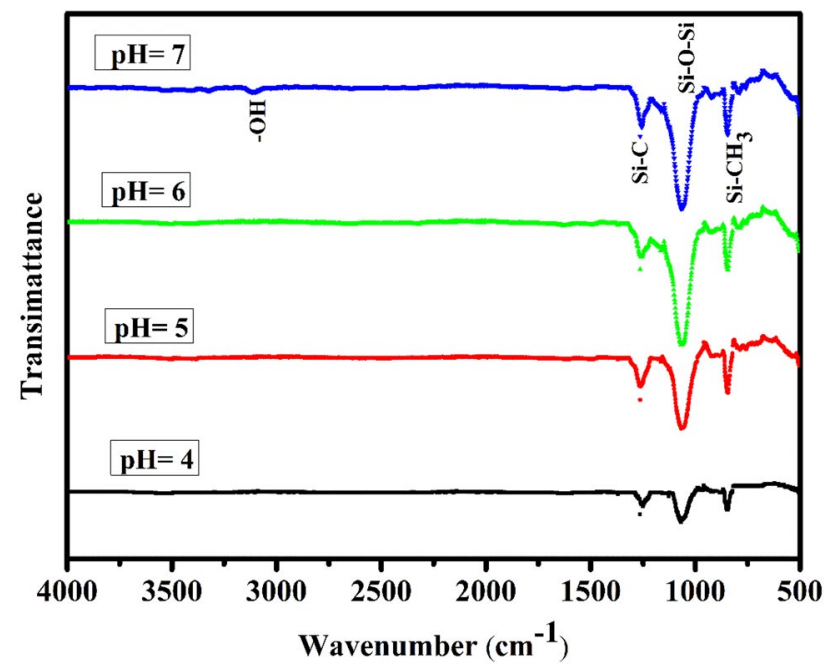

try to an applied external force. The peak at $3120 \mathrm{~cm}^{-1}$ corresponds to the hydrogen-bonded water molecules that is $\mathrm{O}-\mathrm{H}$ stretching band, which shows the unmodified surface of silica aerogels sample.

The microstructural FE-SEM micrographs of prepared samples with $\mathrm{pH}$ variation are shown Fig. 5. The FE-SEM images clearly show the three-dimensional network structure of silica (Si-O-Si) as well as the effect of $\mathrm{pH}$ on the surface morphology of silica aerogel. Effect of preparation $\mathrm{pH}$ $4,5,6,7$ on the morphology of prepared samples can be observed from FE-SEM images $A, B, C$, and $D$ respectively. Figure 5 a gives us information that aerogel for aerogel prepared with $\mathrm{pH} 4$ has a more porous structure which is good agreement with obtained density BET results and the particle size is uniform. The aerogel prepared with silica sol having pH 5 shows (Fig. 5b) porous as well as little bit aggregation also with homogeneity of particle size. The

Fig. 4 The FT-IR spectrum of silica aerogels with different $\mathrm{pH}$ values preparation $\mathrm{pH} 6$ (Fig. 5c) demonstrate that aerogel particles are dense and aggregated [32, 33]. As illustrated in

the $\mathrm{pH}$ of silica aerogel does not affect chemical bonding. In the present study, the hydrophobicity of the prepared sample was tested by putting silica aerogels sample on the water surface. It was observed that the sample was floating above the surface of the water molecule although Fig. $5 \mathrm{~d}$ the silica aerogels prepared with natural condition aerogels particles show aggregation with identical particle size with good 3D structure. At pH 7 for hydrolysis the reaction rate very less hence it gives un-reacted silica networks because of this condition particles get aggregated 

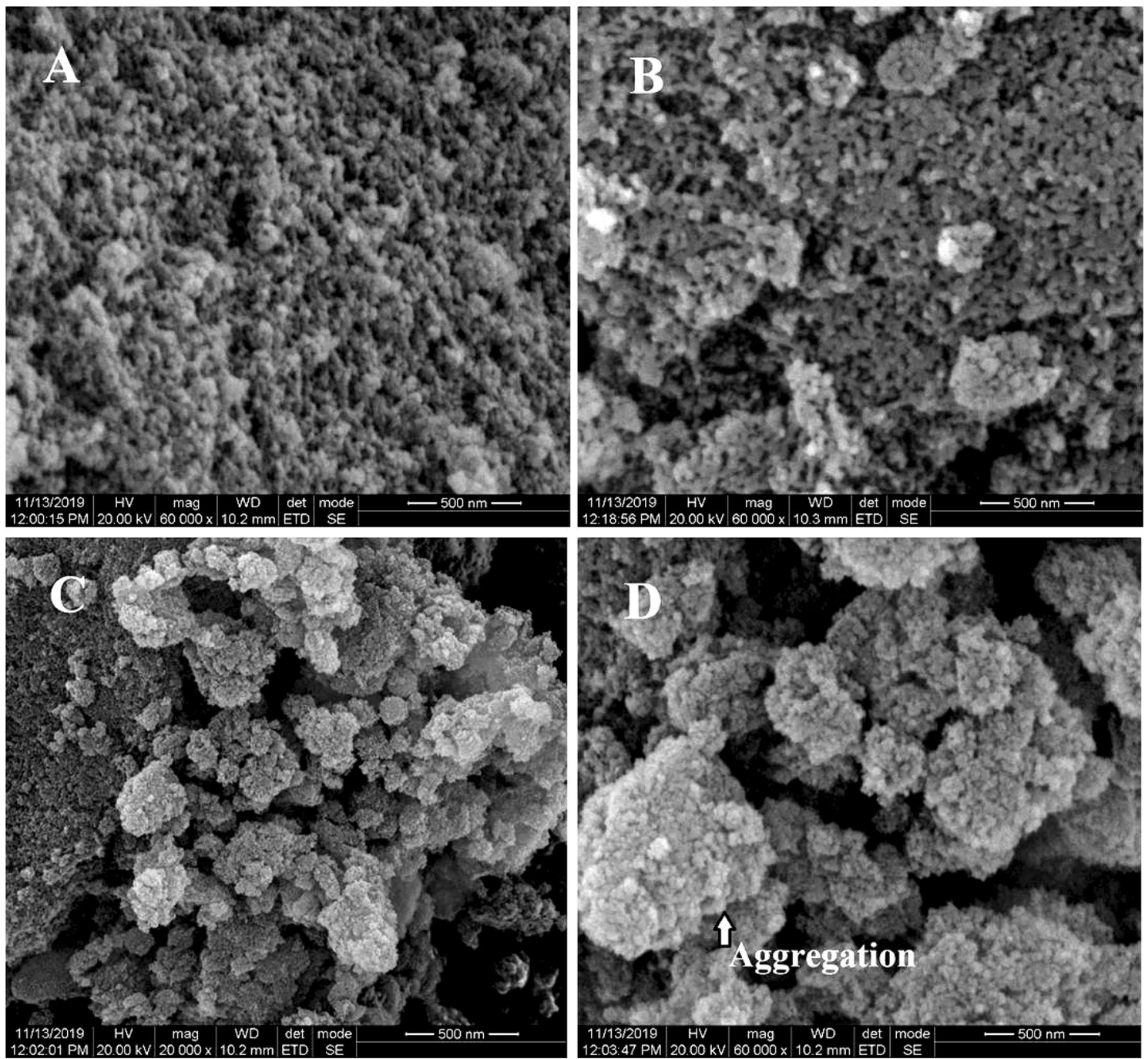

Fig. 5 FE-SEM images of microstructure of silica aerogel with $\mathrm{pH}$ variation

and gives rise to dense particles and lowest surface area as well as density [19].

The elemental analysis of all the prepared samples was carried out by the energy dispersive $\mathrm{X}$-ray analysis (EDAX) coupled with the FE-SEM instrument. Figure 6 displays the EDAX spectra of all the aerogel samples prepared at various $\mathrm{pH}$ values. It is clearly observed from Fig. 6 that, the prepared aerogel samples only consist of the traces of the desired elements i.e. silica (Si), oxygen (O) and carbon (c). The weight and atomic percentage ( $w t \%$ and at.\%) are presented in tabular form in the inset of Fig. 9. The EDAX result reveals the pure form gesture of the prepared aerogel without the presence of any impurity traces.

Transmittance spectra determined via the plot of percentage transmission v/s UV-Vis wavelength is shown in Fig. 7 for the samples prepared at different $\mathrm{pH}$ values. The network structure of the prepared aerogel in the form of silica is the important factor that gives rise to the variation in the transmittance of exposed radiation. In the visible light spectra, scattering of the light increases as the inner surface of the pores of the prepared silica aerogels are more transparent. The light scattering in the prepared aerogels is may due to the divergence in the values of refractive indexes in between the silica network and inner pore of the gel which acts as scattering centers [20]. Samples with $\mathrm{pH}$ values 4,6 and 7 shows relatively low transmittance whereas the sample with $\mathrm{pH}$ value 5 expresses the greater transmittance as shown in Fig. 7.

The nitrogen adsorption-desorption isotherms and the pore size distribution (PSD) curves of the silica aerogels samples were recorded in order to estimate the effect of $\mathrm{pH}$ at which the sodium silicate solution was hydrolyzed are exhibited in Fig. 8. All the prepared samples show greater surface area values such as in rage of $630-892 \mathrm{~m}^{2} / \mathrm{g}$. For the prepared silica aerogel samples the physisorption isotherms were found that of type IV

\section{SN Applied Sciences}



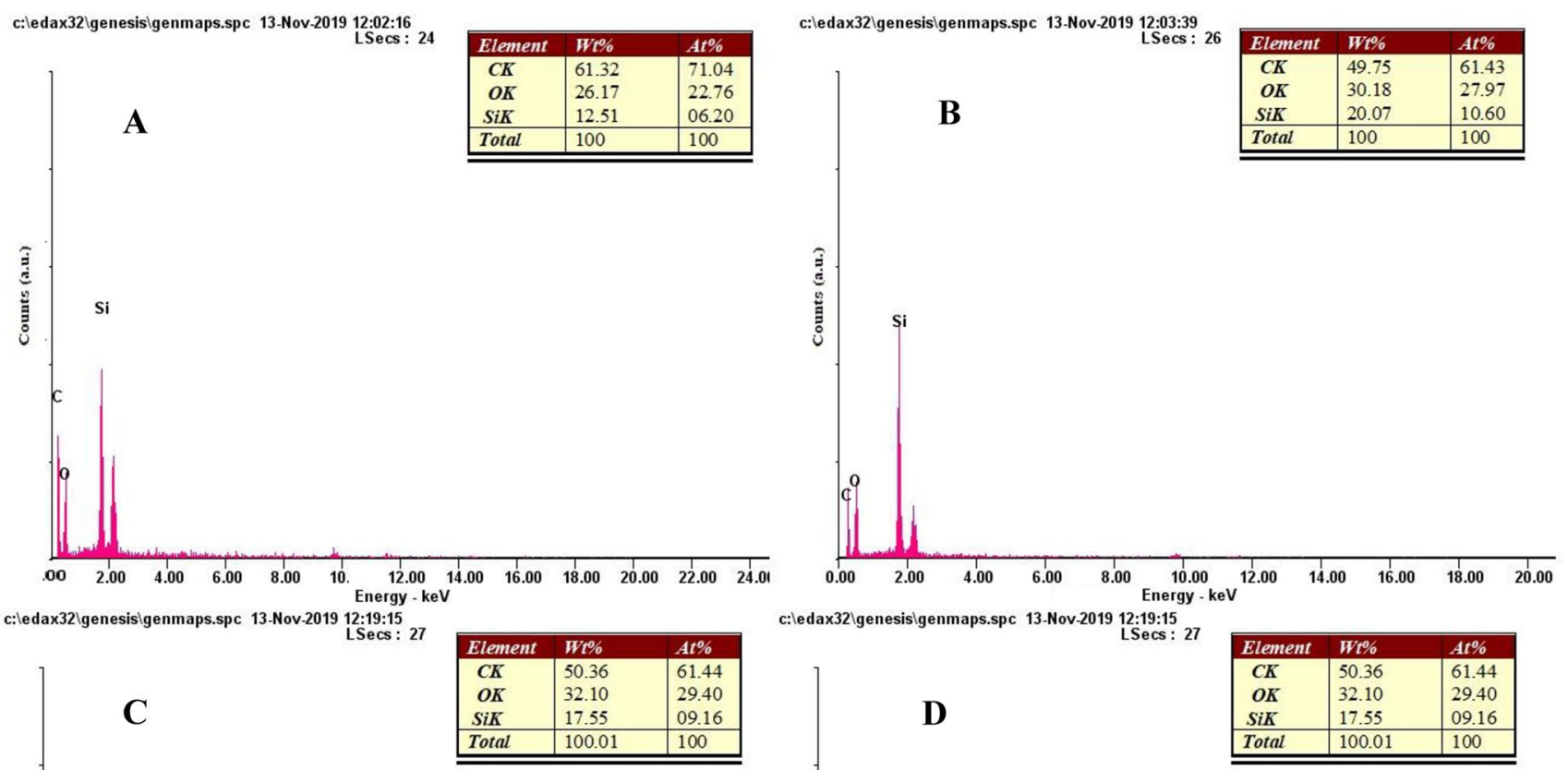
c:ledax32 Igenesisigenmaps.spc 13-Nov-2019 12:19:15
LSecs: 27

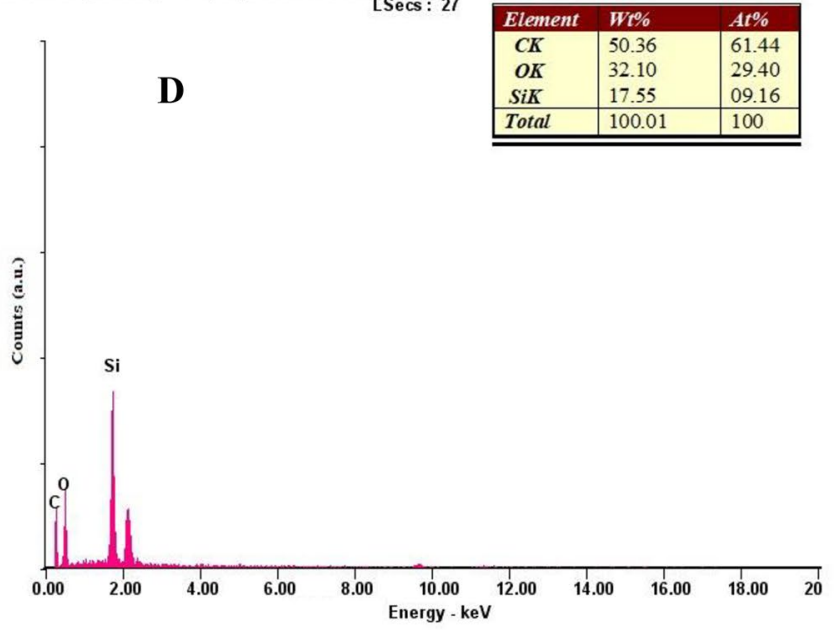

Fig. 6 EDAX spectra of silica aerogel with $\mathrm{pH}$ variation

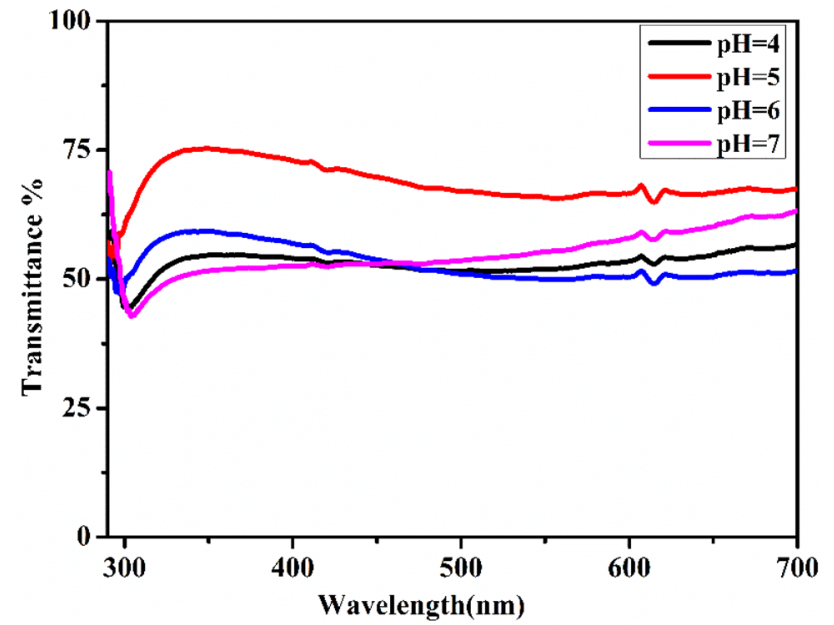

Fig. 7 Transmittance spectra of silica aerogel at different $\mathrm{pH}$ value hysteresis loop [32]. According to IUPAC classification, hysteresis loops, mesoporous materials consistent with type IV hysteresis loops [34-36]. The obtained isotherms plots of silica aerogel with different $\mathrm{pH}$ values indicate mesoporous (2-50 nm) size. In mesoporous materials, the capillary condensation occurs for all samples which give desorption cycles of isotherms. The results disclose that the $\mathrm{pH}$ of wet gel can be significantly influenced by microporous and mesoporous silica aerogels. There is variation in surface area of silica aerogel with $\mathrm{pH}$ value such that at natural condition surface area is less as compared to $\mathrm{pH}$ at 4. At pH 7 (neutral condition) condensation process dominates the hydrolysis process the molecule of precursors aggregates which causes density upsurge and hence the surface area is less [20]. As pH value increase, the surface area of silica decrease, pore radius obtained 19-21 $\AA$, the variation of surface area, pore radius pore volume with respect to $\mathrm{pH}$ are summarized in Table 1. The 

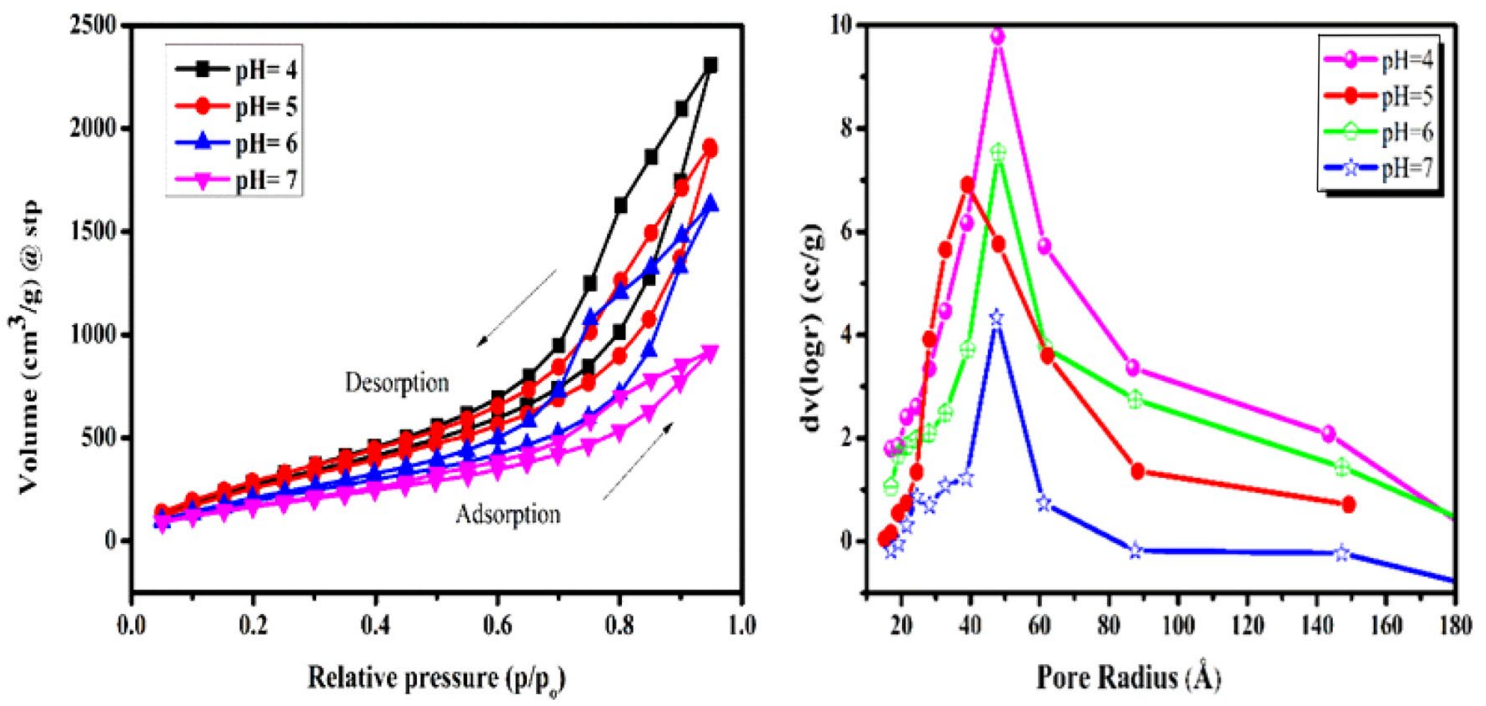

Fig. 8 Nitrogen adsorption-desorption isotherms and pore size distribution of silica aerogel at different $\mathrm{pH}$ value

Table 1 Obtained physical parameters of silica aerogels samples with different $\mathrm{pH}$

\begin{tabular}{lllllll}
\hline $\mathrm{pH}$ value & $\begin{array}{l}\text { Gelation } \\
\text { time }(\mathrm{min})\end{array}$ & $\begin{array}{l}\text { Density } \\
( \pm 0.005)(\mathrm{g} / \\
\left.\mathrm{cm}^{3}\right)\end{array}$ & $\begin{array}{l}\text { Surface area } \\
\left(\mathrm{m}^{2} / \mathrm{g}\right)( \pm 6.246)\end{array}$ & $\begin{array}{l}\text { Pore radius } \\
(\AA)( \pm 0.421)\end{array}$ & $\begin{array}{l}\text { Pore volume } \\
\left(\mathrm{cm}^{3} / \mathrm{g}\right)( \pm 0.082)\end{array}$ & $\begin{array}{l}\text { Thermal } \\
\text { stability } \\
\left({ }^{\circ} \mathrm{C}\right)\end{array}$ \\
\hline 4 & 4 & 0.1005 & 802 & 21.52 & 2.38 & 521 \\
5 & 4 & 0.1091 & 770 & 21.13 & 1.98 & 522 \\
6 & 12 & 0.1445 & 658 & 19.14 & 1.27 & 536 \\
7 & 23 & 0.1802 & 538 & 19.18 & 0.62 & 512 \\
\hline
\end{tabular}

pore volume varies from 0.6 to $2.4 \mathrm{~cm}^{3} / \mathrm{g}$ with $\mathrm{pH}$ variation, Fig. 2 demonstrates that the variation of surface area and pore volume reveal the same nature with preparation $\mathrm{pH}$. The sample prepared at 5 shows more transmittance percentage because of the smaller particle network (radius $<70 \AA$ ) with broad PSD [33]. Result reveals that the preparation $\mathrm{pH}$ of silica sol can be easily used to adjust the surface area, pore-volume, and radius of silica aerogel.

The hydrophobicity is one of the most important aspects of the silica aerogel samples as it governs the many applications. The measurement of the water contact angle is the popular technique to determine the hydrophobic behaviour of the prepared aerogel samples [37, 38]. Figure 9 shows the water contact angle images of the prepared aerogel samples at varying $\mathrm{pH}$ values. The contact angles measured from the images varies in between the $131^{\circ}-149^{\circ}$. As the water contact angle values are greater than $90^{\circ}$, it approves the hydrophobic behaviour of all the samples. The highest value $\left(149^{\circ}\right)$ of the contact angle was observed for the sample having $\mathrm{pH}$ value $\sim 5$, whereas for $\mathrm{pH} \sim 7$, the lowest value $\left(131^{\circ}\right)$ of the contact angle was observed.

\section{Conclusions}

An ambient pressure dried hydrophobic silica aerogels were successfully prepared by the sol-gel technique with the variation of solution $\mathrm{pH}$. The influence $\mathrm{pH}$ on gelation in the form hydrolysis and condensation, as well as density, surface morphology, thermal stability, nanostructure such as specific surface area, pore-volume, and pore radius, was studied. The obtained results imply that preparation $\mathrm{pH}$ strongly affects the physicochemical parameters like thermal steadiness, morphology, surface area, pore radius, and hydrophobicity. The density, thermal stability, BET surface area obtained aerogels sample varied from 0.10 to $0.18 \mathrm{~g} /$ $\mathrm{cm}^{3}, 512$ to $536^{\circ} \mathrm{C}$, and 538 to $802 \mathrm{~m}^{2} / \mathrm{g}$ respectively. The samples prepared with $\mathrm{pH} 5$ shows the highest transmittance. Water contact angle measurements showed 

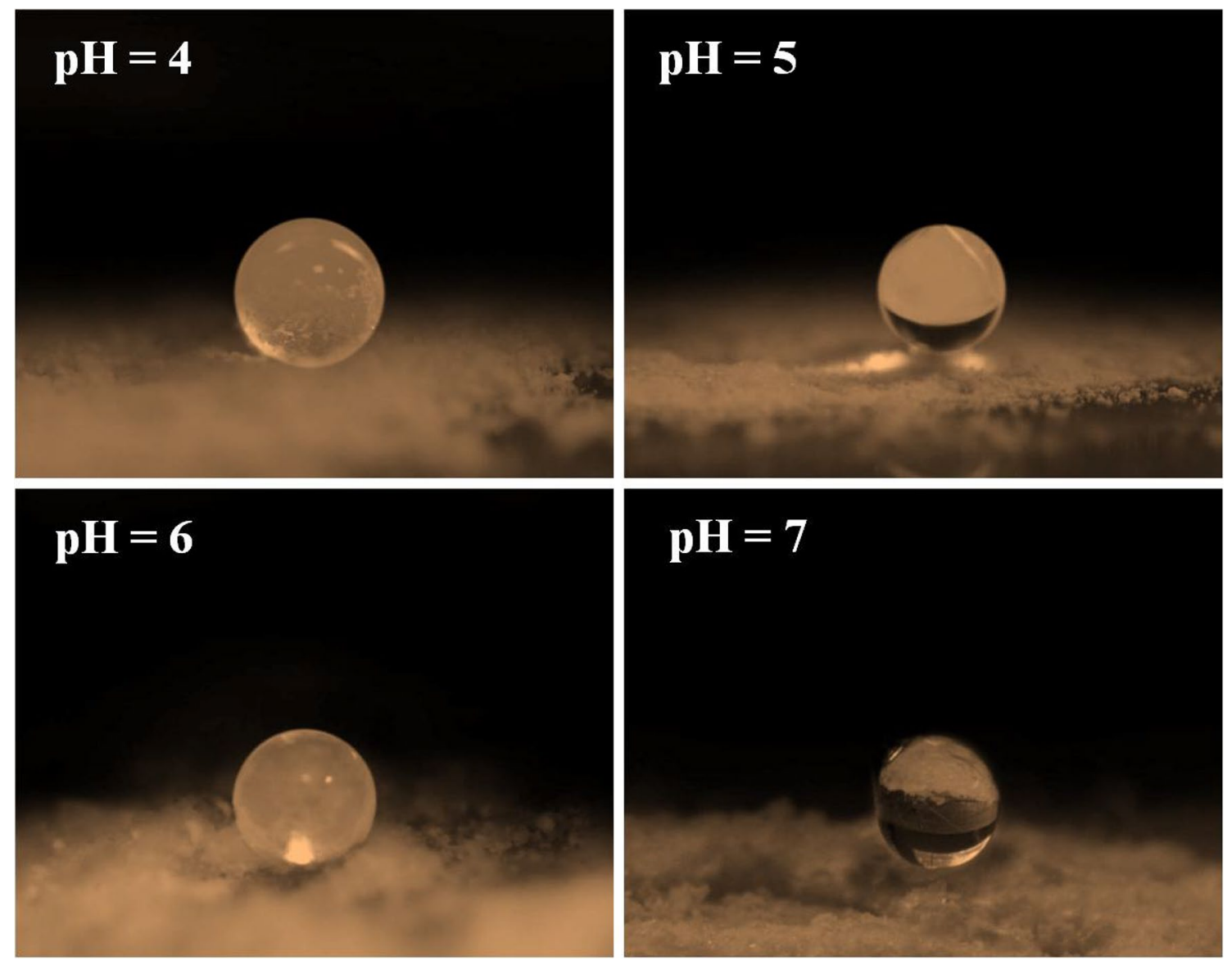

Fig. 9 Water contact angle images of silica aerogel at different $\mathrm{pH}$ value

hydrophobic behaviour of all the samples. The best-quality silica aerogels in order of surface area, thermal stability and high transparency were obtained at for $\mathrm{pH}=5$.

Acknowledgements One of the author MVK is greatful to Dr. A. V. Rao, Retd. Professor, Shivaji University, Kolhapur for his valuable guidance, motivation, and fruitful suggestions. The author MVK acknowledges the FT-IR and TG-DTA measurements provided by Department of Chemistry, Dr. B. A. M. University, A'bad (M.S), India. The author Sandeep B. Somvanshi acknowledges the Department of Science and Technology (DST), Government of India for DST-INSPIRE Fellowship (IF170288).

Author's contribution MVK, investigation, methodology, data curation, formal analysis, Writing - original draft. SAJ, investigation, formal analysis. SBS, investigation, methodology, data curation, formal analysis, writing - original draft, writing - review and editing. PBK, formal analysis, writing-original draft. KMJ, conceptualization, supervision, writing - original draft, writing—review and editing.

\section{Compliance with ethical standards}

Conflict of interest The authors declare that they have no competing interests.

\section{References}

1. Parale VG et al (2017) Flexible and transparent silica aerogels: an overview. J Korean Ceram Soc 54(3):184-199

2. Rao AV (2019) Elastic superhydrophobic and water glass-based silica aerogels and applications. J Sol Gel Sci Technol 90(1):28-54

3. Nah H-Y et al (2018) Role of oxalic acid in structural formation of sodium silicate-based silica aerogel by ambient pressure drying. J Sol Gel Sci Technol 85(2):302-310

4. Parale V et al (2013) Effect of aluminium and copper acetylacetonate on physico-chemical properties of tetraethoxysilane based silica aerogels. J Porous Mater 20(3):563-570

5. Rao AP et al (2007) Effect of solvent exchanging process on the preparation of the hydrophobic silica aerogels by ambient pressure drying method using sodium silicate precursor. J Mater Sci 42(20):8418-8425

6. Parale V et al (2012) Wettability study of surface modified silica aerogels with different silylating agents. J Sol Gel Sci Technol 63(3):573-579

7. Parale VG et al (2018) Facile synthesis of hydrophobic, thermally stable, and insulative organically modified silica aerogels using co-precursor method. Ceram Int 44(4):3966-3972

8. Yun S, Luo H, Gao Y (2014) Superhydrophobic silica aerogel microspheres from methyltrimethoxysilane: rapid synthesis via ambient pressure drying and excellent absorption properties. RSC Adv 4(9):4535-4542 
9. Lee YK et al (2017) Hydrophobic silica composite aerogels using poly (methyl methacrylate) by rapid supercritical extraction process. J Sol Gel Sci Technol 83(3):692-697

10. Pisal AA, Rao AV (2016) Comparative studies on the physical properties of TEOS, TMOS and $\mathrm{Na}_{2} \mathrm{SiO}_{3}$ based silica aerogels by ambient pressure drying method. J Porous Mater 23(6):1547-1556

11. Nah $\mathrm{H}-\mathrm{Y}$ et al (2018) Silylation of sodium silicate-based silica aerogel using trimethylethoxysilane as alternative surface modification agent. J Sol Gel Sci Technol 87(2):319-330

12. Strobach E et al (2017) High temperature annealing for structural optimization of silica aerogels in solar thermal applications. J Non Cryst Solids 462:72-77

13. Reichenauer $G$ (2011) Structural characterization of aerogels. In: Leventis N, Koebel MM, Aegerter MA (eds) Aerogels handbook. Springer, Berlin, pp 449-498

14. Parale VG et al (2018) Ambient pressure dried tetrapropoxysilane-based silica aerogels with high specific surface area. Solid State Sci 75:63-70

15. Dorcheh AS, Abbasi M (2008) Silica aerogel; synthesis, properties and characterization. J Mater Process Technol 199(1-3):10-26

16. Vareda JP et al (2018) Effect of different types of surfactants on the microstructure of methyltrimethoxysilane-derived silica aerogels: a combined experimental and computational approach. J Colloid Interface Sci 512:64-76

17. Brinker CJ, Scherer GW (2013) Sol-gel science: the physics and chemistry of sol-gel processing. Academic Press, Cambridge

18. Kim PBSJ-K, Park J-K, Kim H-K (2006) Influence of solvent exchange on the physical properties of sodium silicate based aerogel prepared at ambient pressure

19. Sinkó K (2010) Influence of chemical conditions on the nanoporous structure of silicate aerogels. Materials 3(1):704-740

20. Twej WA et al (2017) Tuned optical transmittance in single-stepderived silica aerogels through $\mathrm{pH}$-controlled microstructure. Int Nano Lett 7(4):257-265

21. Fidalgo A, Rosa ME, Ilharco LM (2003) Chemical control of highly porous silica xerogels: physical properties and morphology. Chem Mater 15(11):2186-2192

22. Aravind $P$ et al (2010) Ambient pressure drying: a successful approach for the preparation of silica and silica based mixed oxide aerogels. J Sol Gel Sci Technol 54(1):105-117

23. Somvanshi SB et al (2019) Investigations of structural, magnetic and induction heating properties of surface functionalized zinc ferrite nanoparticles for hyperthermia applications. In: AIP conference proceedings. AIP Publishing LLC

24. Kale SB et al (2018) Enhancement in surface area and magnetization of $\mathrm{CoFe}_{2} \mathrm{O}_{4}$ nanoparticles for targeted drug delivery application. In: AIP conference proceedings. AIP Publishing LLC

25. Babrekar M, Jadhav K (2017) Synthesis and characterization of spray deposited lithium ferrite thin film. Int. Res. J. Sci. Eng. Special A1:73-76
26. Rao AV, Nilsen E, Einarsrud M-A (2001) Effect of precursors, methylation agents and solvents on the physicochemical properties of silica aerogels prepared by atmospheric pressure drying method. J Non cryst Solids 296(3):165-171

27. Rao AP, Rao AV, Pajonk G (2007) Hydrophobic and physical properties of the ambient pressure dried silica aerogels with sodium silicate precursor using various surface modification agents. Appl Surf Sci 253(14):6032-6040

28. Khedkar MV et al (2019) Surface modified sodium silicate based superhydrophobic silica aerogels prepared via ambient pressure drying process. J Non Cryst Solids 511:140-146

29. Kow K-W et al (2014) From bamboo leaf to aerogel: preparation of water glass as a precursor. J Non Cryst Solids 386:76-84

30. Sarawade PB et al (2010) Production of low-density sodium silicate-based hydrophobic silica aerogel beads by a novel fast gelation process and ambient pressure drying process. Solid State Sci 12(5):911-918

31. He S et al (2015) Rapid synthesis of sodium silicate based hydrophobic silica aerogel granules with large surface area. Adv Powder Technol 26(2):537-541

32. Sun $D$ et al (2018) Research of silica aerogels prepared by acidic silica sol under the condition of atmospheric pressure drying. $J$ Porous Mater 25(2):341-349

33. Rao AP, Rao AV, Gurav JL (2008) Effect of protic solvents on the physical properties of the ambient pressure dried hydrophobic silica aerogels using sodium silicate precursor. J Porous Mater 15(5):507-512

34. Somvanshi SB et al (2020) Structural, thermal, spectral, optical and surface analysis of rare earth metal ion $\left(\mathrm{Gd}^{3+}\right)$ doped mixed Zn-Mg nano-spinel ferrites. Ceram Int. https://doi.org/10.1016/j. ceramint.2020.02.091

35. Somvanshi SB et al (2019) Influential diamagnetic magnesium $\left(\mathrm{Mg}^{2+}\right)$ ion substitution in nano-spinel zinc ferrite $\left(\mathrm{ZnFe}_{2} \mathrm{O}_{4}\right)$ : thermal, structural, spectral, optical and physisorption analysis. Ceram Int. https://doi.org/10.1016/j.ceramint.2019.12.097

36. Borade RM et al (2020) Spinel zinc ferrite nanoparticles: an active nanocatalyst for microwave irradiated solvent free synthesis of chalcones. Mater Res Express 7:016116

37. Somvanshi SB et al (2019) Hydrophobic to hydrophilic surface transformation of nano-scale zinc ferrite via oleic acid coating: magnetic hyperthermia study towards biomedical applications. Ceram Int. https://doi.org/10.1016/j.ceramint.2019.11.265

38. Kardile $\mathrm{H}$ et al (2020) Effect of $\mathrm{Cd}^{2+}$ doping on structural, morphological, optical, magnetic and wettability properties of nickel ferrite thin films. Optik. https://doi.org/10.1016/j.ijleo .2020 .164462

Publisher's Note Springer Nature remains neutral with regard to jurisdictional claims in published maps and institutional affiliations. 